Injuries related to respiratory masks in the US are very rare

Philip N. Cohen

University of Maryland, College Park

December 17, 2021

\begin{abstract}
Background. Protective facemasks are important for preventing the spread of COVID-19, and almost all Americans have worn them at least some of the time during the pandemic. There are reasonable concerns about some ill effects of mask-wearing, especially for people who wear masks for extended periods, and for the risk of falling as a result of visual obstruction. But there are also unsupported fears and objections stemming from misinformation and fueled by political disputes. Methods. The study analyzed the Consumer Product Safety Commission's National Electronic Injury Surveillance System (NEISS) for 2020, using the product code for Respiratory Protection Devices, and calculated population incidence rates using Census data. Results. The NEISS included 128 cases, representing an estimated 5122 reported injuries in the population (95\% Cl 3322, 6922). The overall rate of injury reports was 1.54 per 100,000 U.S. residents $(95 \% \mathrm{Cl} 1.00,2.08)$. People over age 75 had higher rates than the population overall, with 5.27 injuries per 100,000 (95\% Cl 2.17, 8.37). The most common type of incidents involved facial injuries, rashes, falls, and those that might be considered anxiety-related. Conclusion. Wearing protective face masks is extremely safe, especially in comparison with other common household products, and in light of their protective benefits with regard to prevent the spread of COVID-19. This information may be useful for public health messaging, and for practitioners trying to increase compliance with mask-wearing guidance.
\end{abstract}




\title{
Injuries related to respiratory masks in the US are very rare
}

\author{
Philip N. Cohen \\ University of Maryland, College Park
}

December 17, 2021

\section{Introduction}

Protective facemasks are important for preventing the spread of COVID-19 [1,2], and many jurisdictions and organizations have implemented mask recommendations or requirements in response to the pandemic [3], with salutary effects on reducing disease transmission [4]. Despite confusing official guidance early in the pandemic [5], mask wearing quickly became embraced by large majorities of the U.S. public, with 93\% telling Gallup they had worn a mask in the previous 7 days in August 2020 [6]. Among those over age 65, 97\% reported wearing a mask at least sometimes in a survey from June to October 2020 [7].

There are reasonable concerns about the effects of mask wearing, especially for people who wear them for extended periods (such as healthcare workers), including pressure-related injuries [8], skin conditions [9], and discomfort [10]. However, there is also health related misinformation about the dangers of masks related to carbon dioxide intake or other misconstrued risks [1,11], as well as political objections, fears over threats to civil liberties, and misunderstandings about efficacy that contribute to resistance against public health guidance [12]. In fact, unjustified fears of, or objections to, wearing masks may result in erroneous reports of perceived harms caused by their use [13].

As with any change in behavior by hundreds of millions of people, especially under conditions of stress and uncertainty, isolating the impact of mask wearing on public health (beyond its benefits for reducing disease transmission) is difficult. However, there are reasons to investigate masks as a source of harm or injury, for the purpose of enhanced mitigation and improvement of public messaging. In addition to dermatological effects noted elsewhere [14], masks present a potential trip-and-fall hazard by impairing vision, either directly or by fogging up glasses, especially for older people $[15,16]$. If mask-related injuries are rare, that may be an important piece of information for public health messaging as well.

This is a population-based study of mask-related injuries using data from the Consumer Product Safety Commission's National Electronic Injury Surveillance System for 2020. Based on qualitative assessment of the injury narratives, diagnostic codes, and demographic data, it presents new information about the incidence of several kinds of incidents leading to mask-related injury reports.

\section{Methods}

The Consumer Product Safety Commission's National Electronic Injury Surveillance System (NEISS) provides reports of emergency department visits from a sample of hospitals, with each visit including up to 3 related product codes. This analysis includes incidents in which there was any use of code 1618, Respiratory Protection Devices. Using weights provided by the survey, and the svy function in 
Stata 17, I report weighted estimates of the incidence of injury reports by age and gender, with population rates based on Census estimates [17].

The NEISS includes up to five diagnostic codes, as well as the disposition of the case. However, in the case of masks, with relatively few reports and an unclear expectation for their etiology, it is informative to analyze the narrative text qualitatively and develop categories specific to current circumstances.

\section{Results}

For the 128 cases in the 2020 data file, representing an estimated 5122 reported injuries in the population, based on the survey weights $(95 \% \mathrm{Cl} 3322,6922)$. There were no reported fatalities. The distribution of cases (weighted) is shown in Table 1 , and the incidence rates by age are shown in Figure 1. The overall rate of injury reports was 1.54 per 100,000 U.S. residents $(95 \% \mathrm{Cl} 1.00,2.08)$. People over age 75 had higher rates than the population overall $(p<.05)$, with 5.27 injuries per $100,000(95 \% \mathrm{Cl} 2.17,8.37)$. 
Table 1

Mask-related injury reports, by age and gender: United States, 2020 [95\% Cls]

\begin{tabular}{lcccc}
\multicolumn{2}{c}{ Gender } & \multicolumn{2}{c}{ Total } \\
\hline Age & Male & Female & Cases & Per 100,000 \\
\cline { 2 - 5 } $0-17$ & 370 & 459 & 830 & 1.11 \\
& {$[75,665]$} & {$[70,848]$} & {$[320,1339]$} & {$[0.43,1.79]$} \\
$18-54$ & 719 & 929 & 1649 & 1.03 \\
& {$[317,1122]$} & {$[382,1476]$} & {$[909,2388]$} & {$[0.57,1.49]$} \\
$55-74$ & 492 & 1001 & 1493 & 1.97 \\
& {$[179,805]$} & {$[526,1475]$} & {$[942,2043]$} & {$[1.24,2.70]$} \\
$75+$ & 264 & 887 & 1151 & 5.27 \\
& {$[0,598]$} & {$[384,1390]$} & {$[475,1828]$} & {$[2.17,8.37]$} \\
& & & & \\
Total & 1846 & 3276 & 5122 & 1.54 \\
& {$[1178,2514]$} & {$[2142,4411]$} & {$[3322,6922]$} & {$[1.00,2.08]$} \\
\hline
\end{tabular}

Figure 1

Mask-related injury reports per 100,000: United States, 2020 [95\% Cls]

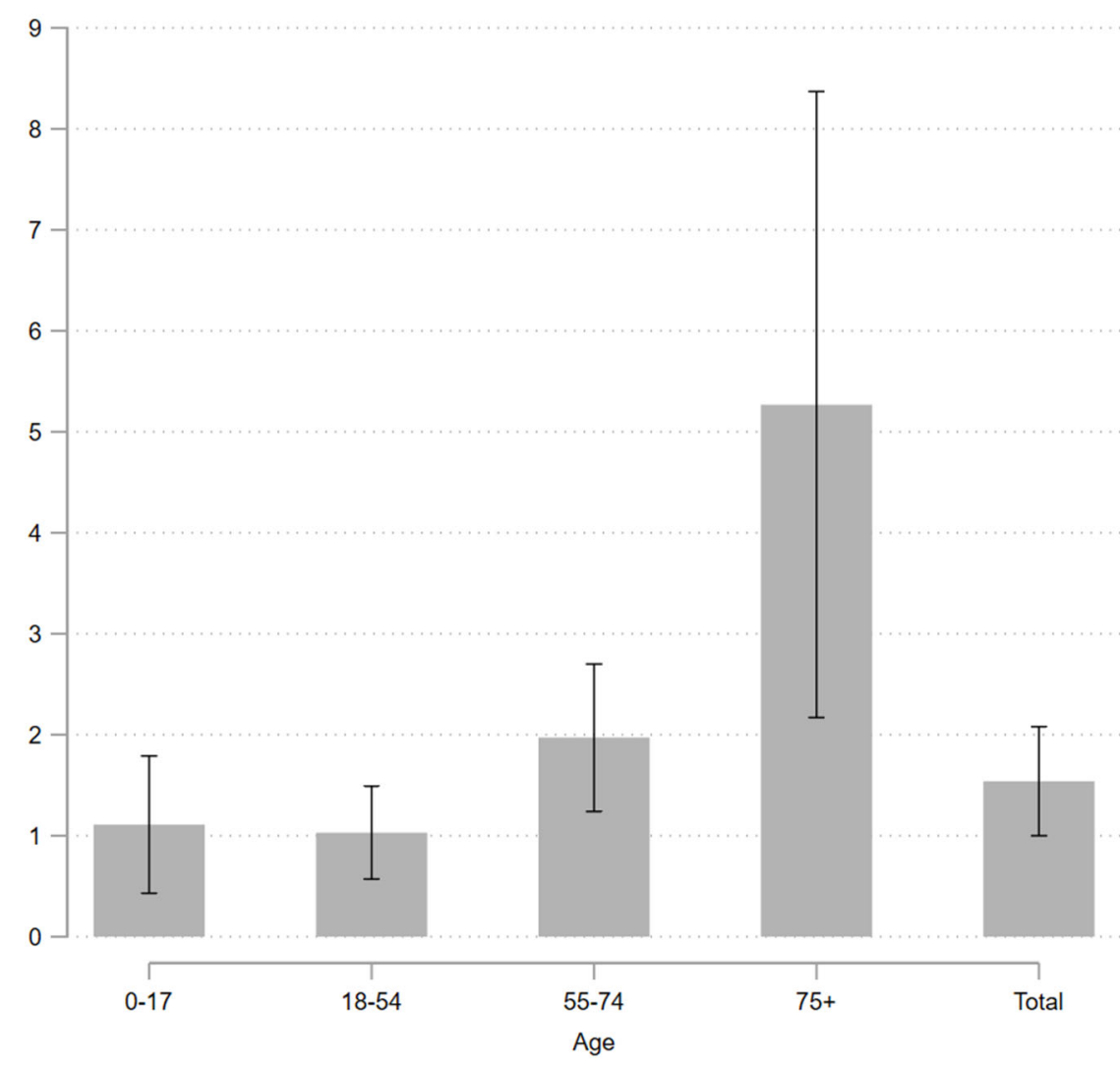




\section{Categories of injury report}

The 8 categories of injury report extracted from the narratives were as follows, in descending order of frequency:

Facial injuries, such as injuries from elastic bands, ear wounds, pokes in the eye $(N=38$; population estimate 1440; 95\% $\mathrm{Cl} 953,1927)$. None of these cases was admitted to the hospital.

Rashes, of which $92 \%$ of cases were diagnosed as dermatitis $(N=38$; population estimate 1303; $95 \% \mathrm{Cl} 623,1983)$. None of these was admitted.

Falls, resulting from attempting to pick up masks, vision obscured by glasses fogging or the mask itself, slipping on masks underfoot, and distractions while putting on a mask ( $N=22$; population estimate 1256; 95\% Cl 522, 1991). Three of these cases were admitted. Those reporting fall-related injuries were significantly older than others ( $M=70.7$ vs. $43.7, p<.05)$.

Fears, a category that includes people reporting shortness of breath, dizziness, syncope, or chest pain that included some attribution to a mask in the narrative $(N=13$; population estimate 510 ; $95 \% \mathrm{Cl} 134,885)$, without hospital admittance. The label "fears" is clearly speculative, but because none of these cases involved admission or reported treatment, it appears they did not involve serious physical injury. Cases include:

- a 68-year-old woman who reported shortness of breath and dizziness, and "feels like her mask was very tight over her face";

- a 31-year-old man who "was getting a haircut and they 'tied a mask on his face too tight'. Says he could not get enough air and now has chest pain";

- a 28-year-old man who "states when he puts on a mask it makes him short of breath causing chest pain"; and,

- a 15-year-old boy who reported "numbness and tingling around his lips when he wears a mask her reports that when he is not wearing a mask he is asymptomatic."

In addition to these major categories, smaller numbers of cases were associated with car crashes involving a driver distracted by a mask $(N=2)$, people injured while making masks $(N=4)$, and cases not easily grouped $(N=11)$.

\section{Conclusions}

From a product safety standpoint, protective respiratory facemasks are extremely safe. Despite being worn at least some of the time by almost all Americans in 2020, there were only an estimated 5122 injuries associated with them, a rate of 1.54 per 100,000 residents. By comparison, as Figure 2 shows (also drawn from the NEISS), there were 18-times as many injuries associated with jewelry, 7-times as many associated with phones and phone accessories, and 4-times as many associated with clothing accessories such as scarves and hats (to compare a few common household items). 


\section{Figure 2}

Injury reports associated with selected products: United States, 2020 [95\% Cls]

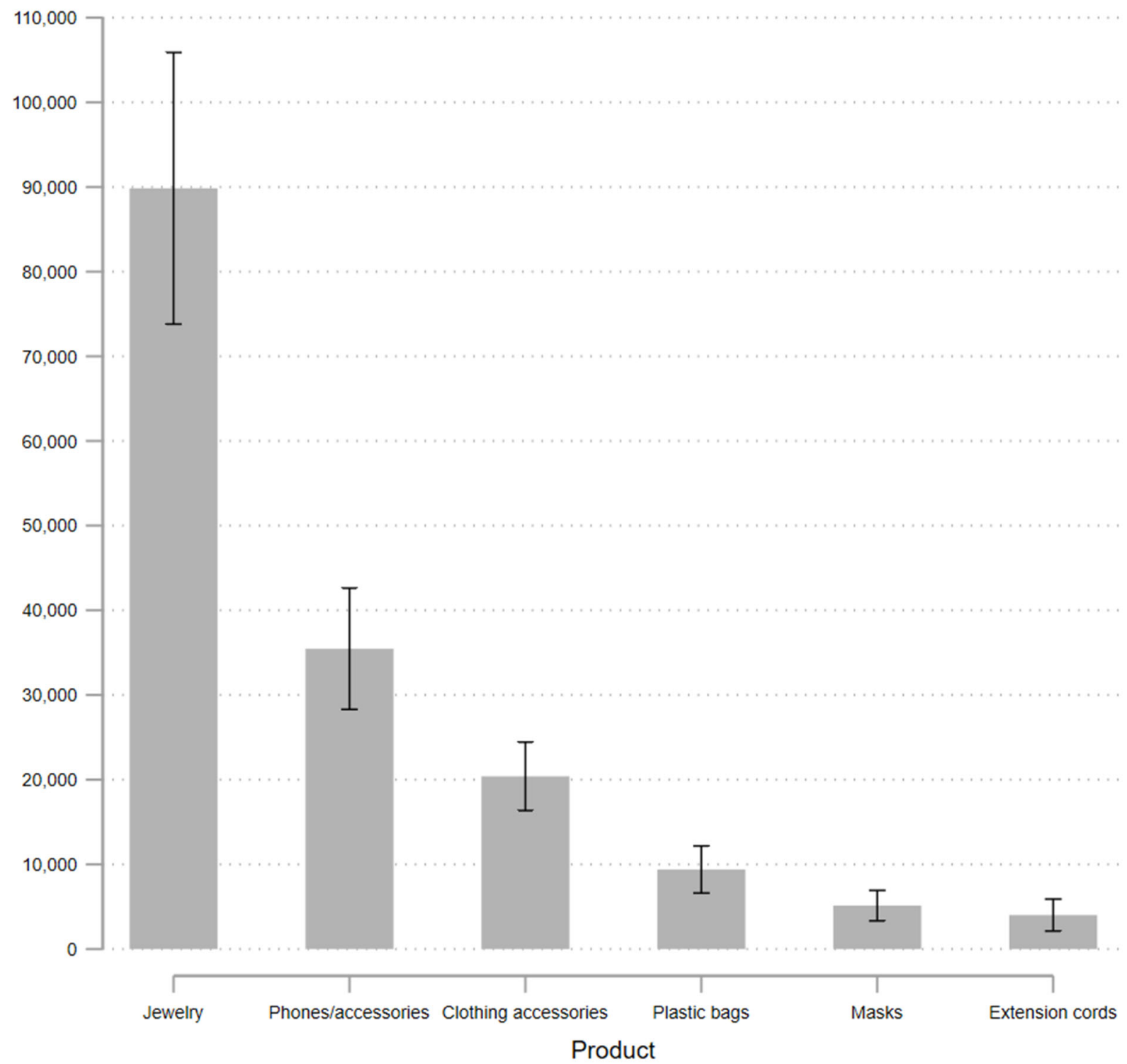

The most concerning type of injuries associated with masks involve falls, especially among older people, for whom masks have caused falls related to fogged glasses, visual obstruction, bending over, and distractions. Observed injury rates are higher for people over age 75. Public health guidance promoting the use of face masks should help prevent such injuries, by encouraging the use of better fitting masks to help prevent fogging and visual obstruction, and cautions against activities that can lead to falling while donning or wearing masks.

In addition, some people report breathing problems and chest pains that they believe are associated with mask wearing, especially when they perceive masks to be constricting their breathing or movement. Although none of these incidents led to hospitalization or reported treatment, in these data, public health campaigns promoting facemasks may benefit from reassuring people of the 
safety of masks. Users and providers may draw confidence from the fact that such events are rare and probably not serious.

\section{References}

1. Howard J, Huang A, Li Z, Tufekci Z, Zdimal V, Westhuizen H-M van der, et al. An evidence review of face masks against COVID-19. PNAS. 2021;118. doi:10.1073/pnas.2014564118

2. World Health Organization. Mask use in the context of COVID-19: interim guidance, 1 December 2020. World Health Organization; 2020. Report No.: WHO/2019-nCoV/IPC_Masks/2020.5. Available: https://apps.who.int/iris/handle/10665/337199

3. Gostin LO, Cohen IG, Koplan JP. Universal Masking in the United States: The Role of Mandates, Health Education, and the CDC. JAMA. 2020;324: 837-838. doi:10.1001/jama.2020.15271

4. Mendez-Brito A, El Bcheraoui C, Pozo-Martin F. Systematic review of empirical studies comparing the effectiveness of non-pharmaceutical interventions against COVID-19. Journal of Infection. 2021;83: 281-293. doi:10.1016/j.jinf.2021.06.018

5. Fazio M. How Mask Guidelines Have Evolved. The New York Times. 27 Apr 2021. Available: https://www.nytimes.com/2021/04/27/science/face-mask-guidelines-timeline.html. Accessed 16 Dec 2021.

6. Saad L. Americans Getting Out More, but Cautiously. In: Gallup.com [Internet]. 7 Jun 2021 [cited 16 Dec 2021]. Available: https://news.gallup.com/poll/350666/americans-gettingcautiously.aspx

7. Probst JC, Crouch EL, Eberth JM. COVID-19 risk mitigation behaviors among rural and urban community-dwelling older adults in summer, 2020. The Journal of Rural Health. 2021;37: 473478. doi:10.1111/jrh.12600

8. Lam U, Md. Mydin Siddik NSF, Mohd Yussof SJ, Ibrahim S. N95 respirator associated pressure ulcer amongst COVID-19 health care workers. Int Wound J. 2020;17: 1525-1527. doi:10.1111/iwj.13398

9. Desai SR, Kovarik C, Brod B, James W, Fitzgerald ME, Preston A, et al. COVID-19 and personal protective equipment: Treatment and prevention of skin conditions related to the occupational use of personal protective equipment. J Am Acad Dermatol. 2020;83: 675-677. doi:10.1016/j.jaad.2020.05.032

10. Bakhit M, Krzyzaniak N, Scott AM, Clark J, Glasziou P, Mar CD. Downsides of face masks and possible mitigation strategies: a systematic review and meta-analysis. BMJ Open. 2021;11: e044364. doi:10.1136/bmjopen-2020-044364

11. Khazan O. How a Bizarre Claim About Masks Has Lived on for Months. In: The Atlantic [Internet]. 9 Oct 2020 [cited 16 Dec 2021]. Available: https://www.theatlantic.com/politics/archive/2020/10/can-masks-make-you-sicker/616641/ 
12. Taylor S, Asmundson GJG. Negative attitudes about facemasks during the COVID-19 pandemic: The dual importance of perceived ineffectiveness and psychological reactance. PLOS ONE. 2021;16: e0246317. doi:10.1371/journal.pone.0246317

13. Christakis D, Fontanarosa PB. Notice of Retraction. Walach $\mathrm{H}$, et al. Experimental Assessment of Carbon Dioxide Content in Inhaled Air With or Without Face Masks in Healthy Children: A Randomized Clinical Trial. JAMA Pediatr. Published online June 30, 2021. JAMA Pediatrics. 2021;175: e213252. doi:10.1001/jamapediatrics.2021.3252

14. McGwin G, McGwin M, Griffin RL. An increase in respiratory protection device injuries associated with the COVID-19 pandemic. Journal of the American Academy of Dermatology. 2021;85: 973-975. doi:10.1016/j.jaad.2021.07.015

15. Kal EC, Young WR, Ellmers TJ. Face masks, vision, and risk of falls. BMJ. 2020;371: m4133. doi:10.1136/bmj.m4133

16. Dankert JF, Virk MS. Mask-Related Glasses Fogging: A Predisposing Mechanism of Falls during the COVID-19 Pandemic. Case Reports in Orthopedics. 2021;2021: e5600216. doi:10.1155/2021/5600216

17. U.S. Census Bureau. 2020 Demographic Analysis (December 2020 release), table 1. 2020 [cited 17 Dec 2021]. Available: https://www2.census.gov/programssurveys/popest/tables/2020/2020-demographic-analysis-estimates/ 